\title{
El jubileo verdadero
}

El jubileo que los profetas anunciaron de parte de Dios para los pobres y cautivos, Jesús lo hace suyo, y lo proclama en el evangelio de Lucas como su programa y proyecto de vida, al afirmar que lo dicho por el profeta Isaías como buena noticia para los pobres, como liberación para los cautivos y como devolución de la vista a los ciegos, se cumplía con su presencia: "Estas palabras que acaban de escuchar - dijo Jesús, tras leer a los profetas-- se están cumpliendo hoy". También nosotros, hoy, en este mismo campus universitario, retomamos esa larga tradición bíblica y cristiana y nos atrevemos a proclamar junto con ustedes que el jubileo anunciado y realizado por Jesús lo queremos hacer nuestro, el jubileo de los pobres y de los excluidos por los poderes de este mundo. Las palabras de Jesús en la sinagoga de Nazaret se cumplieron y se actualizaron en la vida de monseñor Romero y en la vida de todos nuestros mártires, y se están cumpliendo en esta celebración de su memoria viva y en el compromiso por la vida y la justicia, que hoy nosotros queremos continuar asumiendo delante de ellos.

En este año jubilar, proclamado por la Iglesia, nosotros retomamos la palabra de los profetas para decir con ellos que el jubileo es una fiesta, precisamente, porque los pobres celebran que Dios escucha sus clamores, y porque la Iglesia asume su causa para transformar las calamidades humanas y sociales en oportunidad para luchar por una suerte digna y compartida por toda la sociedad. La raíz y experiencia original del jubileo es una veta subversiva, que se constituye en cuestionamiento de las relaciones injustas del presente. Esta veta subversiva, en todas las circunstancias, pero especialmente en tiempos de opresión y de desesperanzas, se constituye en piedra de tropiezo permanente para los opresores, y en reserva mística para los cautivos y oprimidos. Si en la fundación del pueblo de Dios se establecieron relaciones de fraternidad e igualdad, no se puede aceptar que en el presente exista opresión y desigualdad, ni riqueza y abundancia para unos pocos y pobreza y miseria para la mayoría de nuestro pueblo. 
Hoy también se nos pide a la Iglesia, a la comunidad de los cristianos, que vivamos a fondo y en serio el jubileo, constituyéndonos en promotores y constructores permanentes de las alegrías que les han sido quitadas a los pobres. Y, entonces, podremos decir con Jesús "hoy se cumplen las profecías que hemos escuchado". Un jubileo que sea fiesta sin esta memoria profética, sin esta conversión a la justicia y a la fraternidad, pierde su esencia festiva y deja, por tanto, de ser jubileo. El jubileo será auténtico cuando la fiesta y la memoria profética y salvífica de Jesús entronquen con nitidez con un compromiso claro para construir la fraternidad y cuando los clamores de los pequeños y los pobres de la sociedad sean escuchados y concretados en programas específicos de acceso a la tierra, al empleo, de defensa de los derechos de las mujeres y los niños y las niñas, de recuperación y protección del medio ambiente y de una decisión firme para ampliar la democracia también a la economía y a la participación plena de los ciudadanos, en la construcción de un país con una suerte nueva para toda su gente, especialmente para los más pobres.

No dudamos en confesar que la fiesta de nuestros mártires jesuitas, de Elba y Celina, y de todos los mártires salvadoreños y salvadoreñas, como lo hacemos año con año, en este campus universitario, es, ciertamente, una actualización del jubileo, porque esta nuestra fiesta, ésta que nos tiene reunidos esta noche, es expresión cabal de nuestro compromiso por actualizar la palabra y la vida de quienes dieron su vida por la justicia y la dignidad de los pobres y oprimidos.

A nosotros se nos critica que no queremos olvidar ni perdonar. En efecto, no podemos olvidar a nuestros mártires, ni la crueldad con que muchos de ellos fueron asesinados. Pero no los recordamos para odiar, ni para vengarnos. Los recordamos para que la verdad y justicia esclarecida inviten al reconocimiento de la culpa y al perdón -doloroso y lleno de gracia al mismo tiempo-, que nos invita a construir un nuevo país, más justo y solidario.

Celebramos este aniversario también en medio de las voces exaltadas de los poderosos que acusan a la UCA y a la Compañía de Jesús de estar abriendo las heridas de la guerra y de poner en peligro la estabilidad social del país, porque estamos buscando con honradez la verdad y la justicia en el caso del asesinato de nuestros compañeros de la UCA y de Elba y Celina, recurriendo para ello a los medios legales establecidos por las mismas instituciones públicas, que deberían funcionar con la misma imparcialidad para grandes y pequeños. Esto lo consideran ellos intolerancia, que nos impide olvidar y perdonar, y lo consideran ellos soberbia, porque estaríamos buscando, a cual- 


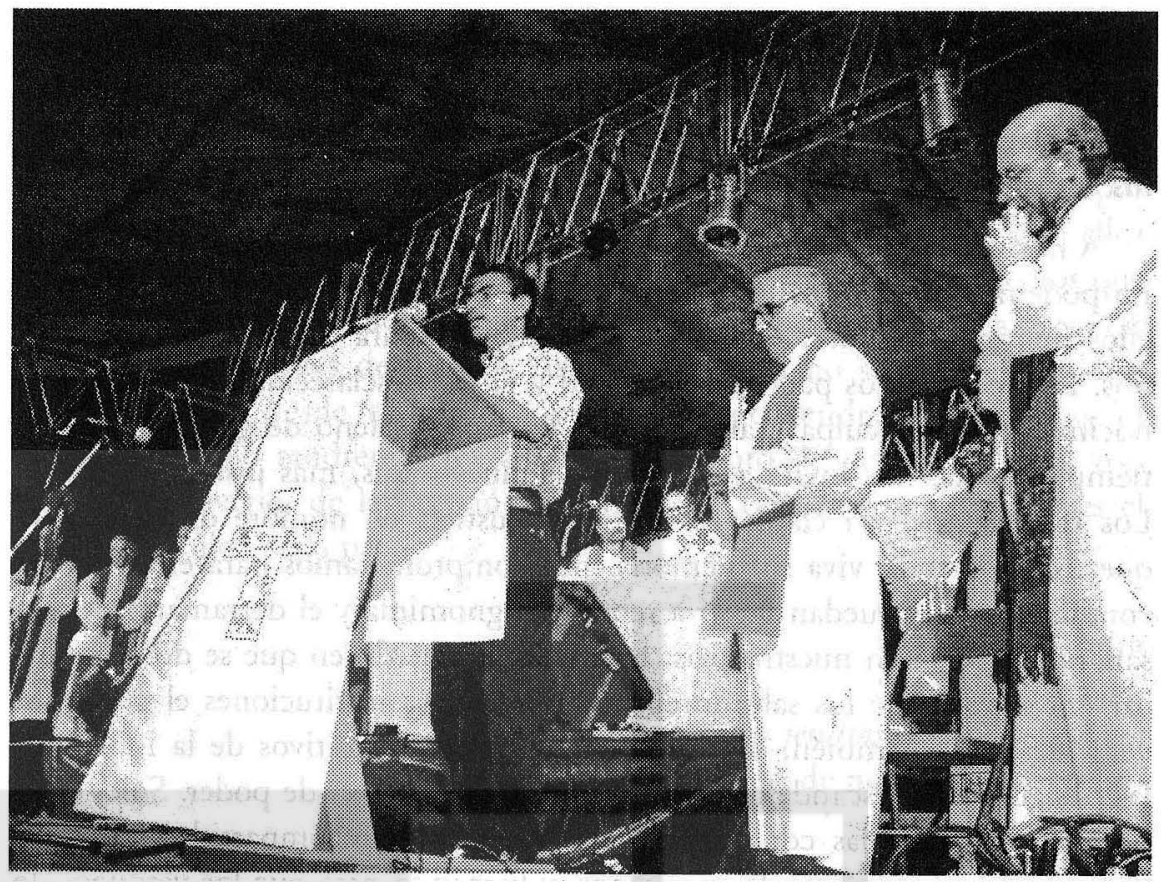

quier costo, diferenciar la muerte de los jesuitas de las miles de muertes que ocurrieron durante el cruento conflicto militar. Lejos de nosotros está querer abrir heridas - éstas siguen todavía abiertas, tal vez tapadas con una leve gasa, que no las deja sanar por no airearse- y más lejos aún de nosotros los jesuitas está el querer distinguirnos y separarnos de los innumerables mártires que nos dieron la vida al entregar la suya de diversas maneras.

La Compañía de Jesús está convencida de que en el esclarecimiento de esta verdad particular se estará esclareciendo también la verdad de muchas muertes más y está convencida de que, si se abre juicio para los autores intelectuales del asesinato de los jesuitas y de Elba y Celina, investigando con seriedad y exhaustivamente, y haciendo justicia apegada a la verdad de lo sucedido, el Estado de derecho y la democracia en nuestro país saldrán fortalecidas y será garantía para que podamos tener una verdadera paz y estabilidad en El Salvador. Las arbitrariedades judiciales, la impunidad y la corrupción, las decisiones que responden de manera favorable a los sectores privilegiados, el abuso de poder de quienes ostentan cargos públicos, la manipulación de las leyes en ventaja de quienes poseen el poder y el dinero, ésos sí son factores desestabilizadores de la sociedad salvadoreña. Así como también son factores desestabilizadores la situación de vulnerabilidad estructural en que viven y sobreviven los sectores mayoritarios urbanos y rurales, para quienes la firma de la paz y la democracia que hemos vivido en la última década, no han significado mayor equidad y justicia, ni una mejor distribución de los bienes producidos por todos, ni un mejor empleo, ni una búsqueda de 
alternativas para nuestra juventud, atrapada en diversas expresiones de violencia, ni una mejor respuesta para el sector rural empobrecido más y más y que reclama un lugar digno en su propio país. Ahí y no en otro lugar están los verdaderos factores desestabilizadores de la sociedad salvadoreña.

A nosotros se nos critica que no queremos olvidar ni perdonar. En efecto, no podemos olvidar a nuestros mártires, ni la crueldad con que muchos de ellos fueron asesinados. Pero no los recordamos para odiar, ni para vengarnos. Los recordamos para que la verdad y justicia esclarecida inviten al reconocimiento de la culpa y al perdón -doloroso y lleno de gracia al mismo tiempo-, que nos invita a construir un nuevo país, más justo y solidario. Los recordamos, y reclamamos verdad y justicia en nombre de ellos, para que, manteniendo viva su memoria, nos comprometamos para erradicar las condiciones que puedan llevar a repetir la ignominia y el derramamiento de sangre fratricida en nuestro país. Estamos de acuerdo en que se debe erradicar del corazón de los salvadoreños y de nuestras instituciones el odio y la venganza, pero también, se deben erradicar los dispositivos de la injusticia, las desigualdades escandalosas, la impunidad y el abuso de poder. Sólo así se podrán establecer las condiciones para un país más compartido, haciendo justicia a las víctimas y a los pequeños, y luchando para que los verdugos de entonces dejen de ser los verdugos del presente. Sólo así avanzaremos hacia un país sin víctimas y sin victimarios, un país, entonces, bañado de perdón y de reconciliación.

En la manera como asumamos nuestro pasado tan duro, así será la calidad de la paz que tendremos en el presente y la calidad de la esperanza con que construiremos el futuro. Si asumimos el pasado echando simplemente un velo sobre él, pero manteniendo viva la impunidad bajo la que se cometieron tantos crímenes, estaremos más bien dejando intactos los dispositivos de la inestabilidad en este país y las condiciones para nuevas confrontaciones sociales y políticas. Si, por el contrario, asumimos con verdad el pasado, haciendo justicia a las víctimas, asumiendo cada uno su propia responsabilidad ante los hechos y pidiendo perdón, diciendo "nunca más", si àsumimos el pasado con el compromiso de consolidar nuestras instituciones para enfrentar los delitos con el derecho y la justicia, defendiendo a las víctimas de cualquier tipo de abusos y de privilegios que brotan del poder y del dinero, si asumimos el pasado poniendo en marcha de verdad programas nacionales que toquen la raíz de la injusticia que provocó el conflicto en el país, estaremos entonces construyendo una paz, ahora sí, firme y duradera, y estaremos poniendo las bases para hacer de El Salvador una verdadera nación libre y soberana, con su gente segura en el presente y con la vista puesta en un futuro lleno de esperanza.

Los mártires son un factor seguro para la paz firme y duradera. Por eso, celebramos su memoria, y con ellos nos comprometemos para que el pasado 
sólo pueda ser fuente de una suerte nueva para la sociedad salvadoreña, y nunca fuente y razón para nuevas y agudas injusticias. Pero para que el pasado no se repita y los mártires brillen como lumbreras, tenemos que seguir siendo tercos e insistentes en la defensa de los pobres y en la lucha por la justicia. Tenemos que dar hoy razón de nuestros mártires, para que ellos sean para nosotros una razón para vivir, como dice la Escritura. Tenemos que recuperar el pasado desde la perspectiva de la verdad y desde ella asegurar procesos transparentes de justicia. Así, el pasado ya no será recordado con amargura, sino desde el perdón, porque ya no tendremos víctimas ni victimarios. Sólo tendremos los abrazos y el canto de un pueblo que, tras salir del cautiverio, de la opresión y la ceguera, celebra con sus mártires el perpetuo jubileo de la paz.

\section{P. Adán Cuadra \\ Superior provincial \\ de los jesuitas de Centroamérica}

San Salvador, 15 de noviembre de 2000. 